\section{An Exploratory Study of Students with Depression in Undergraduate Research Experiences}

\author{
Katelyn M. Cooper, ${ }^{+\# *}$ Logan E. Gin, ${ }^{* \# ~ M . ~ E l i z a b e t h ~ B a r n e s, ~}{ }^{\ddagger}$ and Sara E. Brownell \\ ${ }^{\dagger}$ Department of Biology, University of Central Florida, Orlando, FL, 32816; 'Biology Education \\ Research Lab, Research for Inclusive STEM Education Center, School of Life Sciences, Arizona \\ State University, Tempe, AZ 85281
}

\begin{abstract}
Depression is a top mental health concern among undergraduates and has been shown to disproportionately affect individuals who are underserved and underrepresented in science. As we aim to create a more inclusive scientific community, we argue that we need to examine the relationship between depression and scientific research. While studies have identified aspects of research that affect graduate student depression, we know of no studies that have explored the relationship between depression and undergraduate research. In this study, we sought to understand how undergraduates' symptoms of depression affect their research experiences and how research affects undergraduates' feelings of depression. We interviewed 35 undergraduate researchers majoring in the life sciences from 12 research-intensive public universities across the United States who identify with having depression. Using inductive and deductive coding, we identified that students' depression affected their motivation and productivity, creativity and risk-taking, engagement and concentration, and self-perception and socializing in undergraduate research experiences. We found that students' social connections, experiencing failure in research, getting help, receiving feedback, and the demands of research affected students' depression. Based on this work, we articulate an initial set of evidence-based recommendations for research mentors to consider in promoting an inclusive research experience for students with depression.
\end{abstract}

\section{INTRODUCTION}

Depression is described as a common and serious mood disorder that results in persistent feelings of sadness and hopelessness, as well as a loss of interest in activities that one once enjoyed (American Psychiatric Association [APA], 2013). Additional symptoms of depression include weight changes, difficulty sleeping, loss of energy, difficulty thinking or concentrating, feelings of worthlessness or excessive guilt, and suicidality (APA, 2013). While depression results from a complex interaction of psychological, social, and biological factors (World Health Organization, 2018), studies have shown that increased stress caused by college can be a significant contributor to student depression (Dyson and Renk, 2006).

Depression is one of the top undergraduate mental health concerns, and the rate of depression among undergraduates continues to rise (Center for Collegiate Mental Health, 2017). While we cannot discern whether these increasing rates of depression are due to increased awareness or increased incidence, it is clear that is a serious problem on college campuses. The percent of U.S. college students who self-reported a diagnosis with depression was recently estimated to be about 25\% (American College Health Association, 2019). However, higher rates have been reported, with one study estimating that up to $84 \%$ of undergraduates experience some level of depression (Garlow et al., 2008). Depression rates are typically higher among university students compared with the general population, despite being a more socially privileged group
Stephanie Gardner, Monitoring Editor Submitted Nov 4, 2019; Revised Feb 24, 2020: Accepted Mar 6, 2020

CBE Life Sci Educ June 1, 2020 19:ar19

DOI:10.1187/cbe.19-11-0217

\#These authors contributed equally.

*Address correspondence to: Katelyn M. Cooper (Katelyn.cooper@ucf.edu).

(c) 2020 K. M. Cooper, L. E. Gin, et al. CBE-Life Sciences Education (๑) 2020 The American Society for Cell Biology. This article is distributed by The American Society for Cell Biology under license from the author(s). It is available to the public under an Attribution-NoncommercialShare Alike 3.0 Unported Creative Commons License (http://creativecommons.org/licenses/ by-nc-sa/3.0)

"ASCB $®$ " and "The American Society for Cell Biology $® "$ are registered trademarks of The American Society for Cell Biology. 
(Ibrahim et al., 2013). Prior studies have found that depression is negatively correlated with overall undergraduate academic performance (Hysenbegasi et al., 2005; Deroma et al., 2009; American College Health Association, 2019). Specifically, diagnosed depression is associated with half a letter grade decrease in students' grade point average (Hysenbegasi et al., 2005), and $21.6 \%$ of undergraduates reported that depression negatively affected their academic performance within the last year (American College Health Association, 2019). Provided with a list of academic factors that may be affected by depression, students reported that depression contributed to lower exam grades, lower course grades, and not completing or dropping a course.

Students in the natural sciences may be particularly at risk for depression, given that such majors are noted to be particularly stressful due to their competitive nature and course work that is often perceived to "weed students out"(Everson et al., 1993; Strenta et al., 1994; American College Health Association, 2019; Seymour and Hunter, 2019). Science course instruction has also been described to be boring, repetitive, difficult, and math-intensive; these factors can create an environment that can trigger depression (Seymour and Hewitt, 1997; Osborne and Collins, 2001; Armbruster et al., 2009; Ceci and Williams, 2010). What also distinguishes science degree programs from other degree programs is that, increasingly, undergraduate research experiences are being proposed as an essential element of a science degree (American Association for the Advancement of Science, 2011; President's Council of Advisors on Science and Technology, 2012; National Academies of Sciences, Engineering, and Medicine [NASEM], 2017). However, there is some evidence that undergraduate research experiences can add to the stress of college for some students (Cooper et al., 2019c). Students can garner multiple benefits from undergraduate research, including enhanced abilities to think critically (Ishiyama, 2002; Bauer and Bennett, 2003; Brownell et al., 2015), improved student learning (Rauckhorst et al., 2001; Brownell et al., 2015), and increased student persistence in undergraduate science degree programs (Jones et al., 2010; Hernandez et al., 2018). Notably, undergraduate research experiences are increasingly becoming a prerequisite for entry into medical and graduate programs in science, particularly elite programs (Cooper et al., 2019d). Although some research experiences are embedded into formal lab courses as course-based undergraduate research experiences (CUREs; Auchincloss et al., 2014; Brownell and Kloser, 2015), the majority likely entail working with faculty in their research labs. These undergraduate research experiences in faculty labs are often added on top of a student's normal course work, so they essentially become an extracurricular activity that they have to juggle with course work, working, and/or personal obligations (Cooper et al., 2019c). While the majority of the literature surrounding undergraduate research highlights undergraduate research as a positive experience (NASEM, 2017), studies have demonstrated that undergraduate research experiences can be academically and emotionally challenging for students (Mabrouk and Peters, 2000; Seymour et al., 2004; Cooper et al., 2019c; Limeri et al., 2019). In fact, $50 \%$ of students sampled nationally from public R1 institutions consider leaving their undergraduate research experience prematurely, and about half of those students, or $25 \%$ of all students, ultimately leave their undergraduate research experience (Cooper et al., 2019c). Notably, 33.8\% of these individuals cited a negative lab environment and $33.3 \%$ cited negative relationships with their mentors as factors that influenced their decision about whether to leave (Cooper et al., 2019c). Therefore, students' depression may be exacerbated in challenging undergraduate research experiences, because studies have shown that depression is positively correlated with student stress (Hish et al., 2019).

While depression has not been explored in the context of undergraduate research experiences, depression has become a prominent concern surrounding graduate students conducting scientific research. A recent study that examined the "graduate student mental health crisis" (Flaherty, 2018) found that worklife balance and graduate students' relationships with their research advisors may be contributing to their depression (Evans et al., 2018). Specifically, this survey of $2279 \mathrm{PhD}$ and master's students from diverse fields of study, including the biological/physical sciences, showed that $39 \%$ of graduate students have experienced moderate to severe depression. Fifty-five percent of the graduate students with depression who were surveyed disagreed with the statement "I have good work life balance," compared to only $21 \%$ of students with depression who agreed. Additionally, the study highlighted that more students with depression disagreed than agreed with the following statements: their advisors provided "real" mentorship, their advisors provided ample support, their advisors positively impacted their emotional or mental well-being, their advisors were assets to their careers, and they felt valued by their mentors. Another recent study identified that depression severity in biomedical doctoral students was significantly associated with graduate program climate, a perceived lack of employment opportunities, and the quality of students' research training environment (Nagy et al., 2019). Environmental stress, academic stress, and family and monetary stress have also been shown to be predictive of depression severity in biomedical doctoral students (Hish et al., 2019). Further, one study found that self-esteem is negatively correlated and stress is positively correlated with graduate student depression; presumably research environments that challenge students' self-esteem and induce stress are likely contributing to depressive symptoms among graduate students (Kreger, 1995). While these studies have focused on graduate students, and there are certainly notable distinctions between graduate and undergraduate research, the research-related factors that affect graduate student depression, including work-life balance, relationships with mentors, research environment, stress, and self-esteem, may also be relevant to depression among undergraduates conducting research. Importantly, undergraduates in the United States have reported identical levels of depression as graduate students but are often less likely to seek mental health care services (Wyatt and Oswalt, 2013), which is concerning if undergraduate research experiences exacerbate depression.

Based on the literature on the stressors of undergraduate research experiences and the literature identifying some potential causes of graduate student depression, we identified three aspects of undergraduate research that may exacerbate undergraduates' depression. Mentoring: Mentors can be an integral part of a students' research experience, bolstering their connections with others in the science community, scholarly productivity, and science identity, as well as providing many other benefits 
(Thiry and Laursen, 2011; Prunuske et al., 2013; Byars-Winston et al., 2015; Aikens et al., 2016, 2017; Thompson et al., 2016; Estrada et al., 2018). However, recent literature has highlighted that poor mentoring can negatively affect undergraduate researchers (Cooper et al., 2019c; Limeri et al., 2019). Specifically, one study of 33 undergraduate researchers who had conducted research at 10 institutions identified seven major ways that they experienced negative mentoring, which included absenteeism, abuse of power, interpersonal mismatch, lack of career support, lack of psychosocial support, misaligned expectations, and unequal treatment (Limeri et al., 2019). We hypothesize negative mentoring experiences may be particularly harmful for students with depression, because support, particularly social support, has been shown to be important for helping individuals with depression cope with difficult circumstances (Aneshensel and Stone, 1982; Grav et al., 2012). Failure: Experiencing failure has been hypothesized to be an important aspect of undergraduate research experiences that may help students develop some the most distinguishing abilities of outstanding scientists, such as coping with failure, navigating challenges, and persevering (Laursen et al., 2010; Gin et al., 2018; Henry et al., 2019). However, experiencing failure and the stress and fatigue that often accompany it may be particularly tough for students with depression (Aldwin and Greenberger, 1987; Mongrain and Blackburn, 2005). Lab environment: Fairness, inclusion/exclusion, and social support within one's organizational environment have been shown to be key factors that cause people to either want to remain in the work place and be productive or to want to leave (Barak et al., 2006; Cooper et al., 2019c). We hypothesize that dealing with exclusion or a lack of social support may exacerbate depression for some students; patients with clinical depression react to social exclusion with more pronounced negative emotions than do individuals without clinical depression (Jobst et al., 2015). While there are likely other aspects of undergraduate research that affect student depression, we hypothesize that these factors have the potential to exacerbate negative research experiences for students with depression.

Depression has been shown to disproportionately affect many populations that are underrepresented or underserved within the scientific community, including females (American College Health Association, 2018; Evans et al., 2018), first-generation college students (Jenkins et al., 2013), individuals from low socioeconomic backgrounds (Eisenberg et al., 2007), members of the LGBTQ+ community (Eisenberg et al., 2007; Evans et al., 2018), and people with disabilities (Turner and Noh, 1988). Therefore, as the science community strives to be more diverse and inclusive (Intemann, 2009), it is important that we understand more about the relationship between depression and scientific research, because negative experiences with depression in scientific research may be contributing to the underrepresentation of these groups. Specifically, more information is needed about how the research process and environment of research experiences may affect depression.

Given the high rate of depression among undergraduates, the links between depression and graduate research, the potentially challenging environment of undergraduate research, and how depression could disproportionately impact students from underserved communities, it is imperative to begin to explore the relationship between scientific research and depression among undergraduates to create research experiences that could maximize student success. In this exploratory interview study, we aimed to 1) describe how undergraduates' symptoms of depression affect their research experiences, 2) understand how undergraduate research affects students' feelings of depression, and 3) identify recommendations based on the literature and undergraduates' reported experiences to promote a positive research experience for students with depression.

\section{METHODS}

This study was done with an approved Arizona State University Institutional Review Board protocol \#7247.

In Fall 2018, we surveyed undergraduate researchers majoring in the life sciences across 25 research-intensive (R1) public institutions across the United States (specific details about the recruitment of the students who completed the survey can be found in Cooper et al. (2019c)). The survey asked students for their opinions about their undergraduate research experiences and their demographic information and whether they would be interested in participating in a follow-up interview related to their research experiences. For the purpose of this study, we exclusively interviewed students about their undergraduate research experiences in faculty member labs; we did not consider students' experiences in CUREs. Of the 768 undergraduate researchers who completed the survey, 65\% $(n=496)$ indicated that they would be interested in participating in a follow-up interview. In Spring 2019, we emailed the 496 students, explaining that we were interested in interviewing students with depression about their experiences in undergraduate research. Our specific prompt was: "If you identify as having depression, we would be interested in hearing about your experience in undergraduate research in a 30-60 minute online interview." We did not define depression in our email recruitment because we conducted think-aloud interviews with four undergraduates who all correctly interpreted what we meant by depression (APA, 2013). We had 35 students agree to participate in the interview study. The interview participants represented 12 of the $25 \mathrm{R} 1$ public institutions that were represented in the initial survey.

\section{Student Interviews}

We developed an interview script to explore our research questions. Specifically, we were interested in how students' symptoms of depression affect their research experiences, how undergraduate research negatively affects student depression, and how undergraduate research positively affects student depression.

We recognized that mental health, and specifically depression, can be a sensitive topic to discuss with undergraduates, and therefore we tried to minimize any discomfort that the interviewees might experience during the interview. Specifically, we conducted think-aloud interviews with three graduate students who self-identified with having depression at the time of the interview. We asked them to note whether any interview questions made them uncomfortable. We also sought their feedback on questions given their experiences as persons with depression who had once engaged in undergraduate research. We revised the interview protocol after each thinkaloud interview. Next, we conducted four additional thinkaloud interviews with undergraduates conducting basic 
science or biology education research who identified with having depression to establish cognitive validity of the questions and to elicit additional feedback about any questions that might make someone uncomfortable. The questions were revised after each think-aloud interview until no question was unclear or misinterpreted by the students and we were confident that the questions minimized students' potential discomfort (Trenor et al., 2011). A copy of the final interview script can be found in the Supplemental Material.

All interviews were individually conducted by one of two researchers (K.M.C. and L.E.G.) who conducted the think-aloud interviews together to ensure that their interviewing practices were as similar as possible. The interviews were approximately an hour long, and students received a \$15 gift card for their participation.

\section{Personal, Research, and Depression Demographics}

All student demographics and information about students' research experiences were collected using the survey distributed to students in Fall 2018. We collected personal demographics, including the participants' gender, race/ethnicity, college generation status, transfer status, financial stability, year in college, major, and age. We also collected information about the students' research experiences, including the length of their first research experiences, the average number of hours they spend in research per week, how they were compensated for research, who their primary mentors were, and the focus areas of their research.

In the United States, mental healthcare is disproportionately unavailable to Black and Latinx individuals, as well as those who come from low socioeconomic backgrounds (Kataoka et al., 2002; Howell and McFeeters, 2008; Santiago et al., 2013). Therefore, to minimize a biased sample, we invited anyone who identified with having depression to participate in our study; we did not require students to be diagnosed with depression or to be treated for depression in order to participate. However, we did collect information about whether students had been formally diagnosed with depression and whether they had been treated for depression. After the interview, all participants were sent a link to a short survey that asked them if they had ever been diagnosed with depression and how, if at all, they had ever been treated for depression. A copy of these survey questions can be found in the Supplemental Material. The combined demographic information of the participants is in Table 1. The demographics for each individual student can be found in the Supplemental Material.

\section{Interview Analysis}

The initial interview analysis aimed to explore each idea that a participant expressed (Charmaz, 2006) and to identify reoccurring ideas throughout the interviews. First, three authors (K.M.C., L.E.G., and S.E.B.) individually reviewed a different set of 10 interviews and took detailed analytic notes (Birks and Mills, 2015). Afterward, the authors compared their notes and identified reoccurring themes throughout the interviews using open coding methods (Saldaña, 2015).

Once an initial set of themes was established, two researchers (K.M.C. and L.E.G.) individually reviewed the same set of 15 randomly selected interviews to validate the themes identified in the initial analysis and to screen for any additional themes that the initial analysis may have missed. Each researcher took detailed analytic notes throughout the review of an interview, which they discussed after reviewing each interview. The researchers compared what quotes from each interview they categorized into each theme. Using constant comparison methods, they assigned quotes to each theme and constantly compared the quotes to ensure that each quote fit within the description of the theme (Glesne and Peshkin, 1992). In cases in which quotes were too different from other quotes, a new theme was created. This approach allowed for multiple revisions of the themes and allowed the authors to define a final set of codes; the researchers created a final codebook with refined definitions of emergent themes (the final coding rubric can be found in the Supplemental Material). Once the final codebook was established, the researchers (K.M.C. and L.E.G.) individually coded seven additional interviews (20\% of all interviews) using the coding rubric. The researchers compared their codes, and their Cohen's $\kappa$ interrater score for these seven interviews was at an acceptable level ( $\kappa=0.88$; Landis and Koch, 1977). One researcher (L.E.G.) coded the remaining 28 out of 35 interviews. The researchers determined that data saturation had been reached with the current sample and no further recruitment was needed (Guest et al., 2006). We report on themes that were mentioned by at least $20 \%$ of students in the interview study. In the Supplemental Material, we provide the final coding rubric with the number of participants whose interview reflected each theme (Hannah and Lautsch, 2011). Reporting the number of individuals who reported themes within qualitative data can lead to inaccurate conclusions about the generalizability of the results to a broader population. These qualitative data are meant to characterize a landscape of experiences that students with depression have in undergraduate research rather than to make claims about the prevalence of these experiences (Glesne and Peshkin, 1992). Because inferences about the importance of these themes cannot be drawn from these counts, they are not included in the results of the paper (Maxwell, 2010). Further, the limited number of interviewees made it not possible to examine whether there were trends based on students' demographics or characteristics of their research experiences (e.g., their specific area of study). Quotes were lightly edited for clarity by inserting clarification brackets and using ellipses to indicate excluded text. Pseudonyms were given to all students to protect their privacy.

\section{RESULTS \\ The Effect of Depressive Symptoms on Undergraduate Research}

We asked students to describe the symptoms associated with their depression. Students described experiencing anxiety that is associated with their depression; this could be anxiety that precedes their depression or anxiety that results from a depressive episode or a period of time when an individual has depression symptoms. Further, students described difficulty getting out of bed or leaving the house, feeling tired, a lack of motivation, being overly self-critical, feeling apathetic, and having difficulty concentrating. We were particularly interested in how students' symptoms of depression affected their experiences in undergraduate research. During the think-aloud interviews that were conducted before the interview study, graduate and undergraduate students consistently described that their 
TABLE 1. Student-level demographics, research demographics, and depression demographics of the 35 interview participants

\begin{tabular}{|c|c|c|c|c|c|}
\hline Student-level demographics & $\begin{array}{c}\text { Interview } \\
\text { participants } \\
n=35 \\
n(\%)\end{array}$ & Research demographics & $\begin{array}{c}\text { Interview } \\
\text { participants } \\
n=35 \\
n(\%)\end{array}$ & Depression demographics & $\begin{array}{c}\text { Interview } \\
\text { participants } \\
n=35 \\
n(\%) \\
\end{array}$ \\
\hline Gender & & Length of research ${ }^{\mathrm{a}}$ & & Clinical diagnosis & \\
\hline Female & $27(77 \%)$ & Less than 6 months & $7(20 \%)$ & Yes & $21(60 \%)$ \\
\hline Male & $7(23 \%)$ & 6 months & $6(17 \%)$ & No & $10(29 \%)$ \\
\hline Declined to state & $1(3 \%)$ & 1 year & $11(31 \%)$ & Declined to state & $4(11 \%)$ \\
\hline Race/ethnicity & & 1.5 years & $4(11 \%)$ & Treatment for depression $^{\mathrm{b}}$ & \\
\hline Asian & $9(26 \%)$ & 2 years & $2(6 \%)$ & Medication & $15(43 \%)$ \\
\hline Black & $1(3 \%)$ & 3 years & $3(9 \%)$ & Counseling & $17(49 \%)$ \\
\hline Latinx & $5(14 \%)$ & 3.5 years & $1(3 \%)$ & Other & $2(6 \%)$ \\
\hline Middle Eastern & $1(3 \%)$ & Declined to state & $1(3 \%)$ & No treatment & $15(43 \%)$ \\
\hline Mixed race & $1(3 \%)$ & Hours spent in research/week & & Declined to state & $2(6 \%)$ \\
\hline White & $17(49 \%)$ & $1-5$ hours & $6(17 \%)$ & & \\
\hline Declined to state & $1(3 \%)$ & 6-10 hours & $16(46 \%)$ & & \\
\hline College generation status & & 11-15 hours & $7(20 \%)$ & & \\
\hline First generation & $10(29 \%)$ & $16+$ hours & $5(14 \%)$ & & \\
\hline Continuing generation & $24(69 \%)$ & Declined to state & $1(3 \%)$ & & \\
\hline Declined to state & $1(3 \%)$ & Research compensation $^{c}$ & & & \\
\hline Transfer status & & Money & $13(37 \%)$ & & \\
\hline Transfer & $5(14 \%)$ & Course credit & $24(69 \%)$ & & \\
\hline Nontransfer & $29(83 \%)$ & Volunteer & $7(20 \%)$ & & \\
\hline Declined to state & $1(3 \%)$ & Declined to state & $2(6 \%)$ & & \\
\hline Financially stable $^{\mathrm{d}}$ & & Primary mentor ${ }^{\mathrm{e}}$ & & & \\
\hline No & $6(17 \%)$ & PI & $9(26 \%)$ & & \\
\hline Yes, but only sometimes & $12(34 \%)$ & Postdoc & $3(9 \%)$ & & \\
\hline Yes & $16(46 \%)$ & Graduate student & $14(40 \%)$ & & \\
\hline Declined to state & $1(3 \%)$ & Staff member ${ }^{\mathrm{f}}$ & $7(20 \%)$ & & \\
\hline Year in college & & Undergraduate student & $1(3 \%)$ & & \\
\hline First year & $1(3 \%)$ & Declined to state & $1(3 \%)$ & & \\
\hline Second year & $5(14 \%)$ & Focus area of research & & & \\
\hline Third year & $6(17 \%)$ & Cell/molecular biology & $4(11 \%)$ & & \\
\hline Fourth year or greater & $22(63 \%)$ & Ecology/evolution & $9(26 \%)$ & & \\
\hline Declined to state & $1(3 \%)$ & Genetics & $5(14 \%)$ & & \\
\hline Major & & Immunology & $4(11 \%)$ & & \\
\hline Biology & $32(91 \%)$ & Neuroscience & $3(9 \%)$ & & \\
\hline Biochemistry & $2(6 \%)$ & Physiology/health & $3(9 \%)$ & & \\
\hline Declined to state & $1(3 \%)$ & Other ${ }^{g}$ & $6(17 \%)$ & & \\
\hline Age & & Declined to state & $1(3 \%)$ & & \\
\hline $18-19$ & $5(14 \%)$ & & & & \\
\hline $20-21$ & $17(49 \%)$ & & & & \\
\hline $22-23$ & $11(31 \%)$ & & & & \\
\hline 24 or older & $1(3 \%)$ & & & & \\
\hline Declined to state & $1(3 \%)$ & & & & \\
\hline
\end{tabular}

aStudents reported the time they had spent in research 6 months before being interviewed and only reported on the length of time of their first research experiences. bStudents were invited to report multiple ways in which they were treated for their depression; other treatments included lifestyle changes and meditation. 'Students were invited to report multiple means of compensation for their research if they had been compensated for their time in different ways.

${ }^{\mathrm{d} S}$ Students were asked whether they felt financially stable, particularly during the undergraduate research experience.

eStudents reported who they work/worked with most closely during their research experiences.

fStaff members included lab coordinators or lab managers.

${ }^{8}$ Other focus areas of research included sociology, linguistics, psychology, and public health.

depression affected their motivation in research, their creativity in research, and their productivity in research. Therefore, we explicitly asked undergraduate researchers how, if at all, their depression affected these three factors. We also asked students to describe any additional ways in which their depression affected their research experiences. Undergraduate researchers commonly described five additional ways in which their depression affected their research; for a detailed description of each way students' research was affected and for example quotes, see Table 2. Students described that their depression negatively affected their productivity in the lab. Commonly, students described that their productivity was directly affected by a lack 


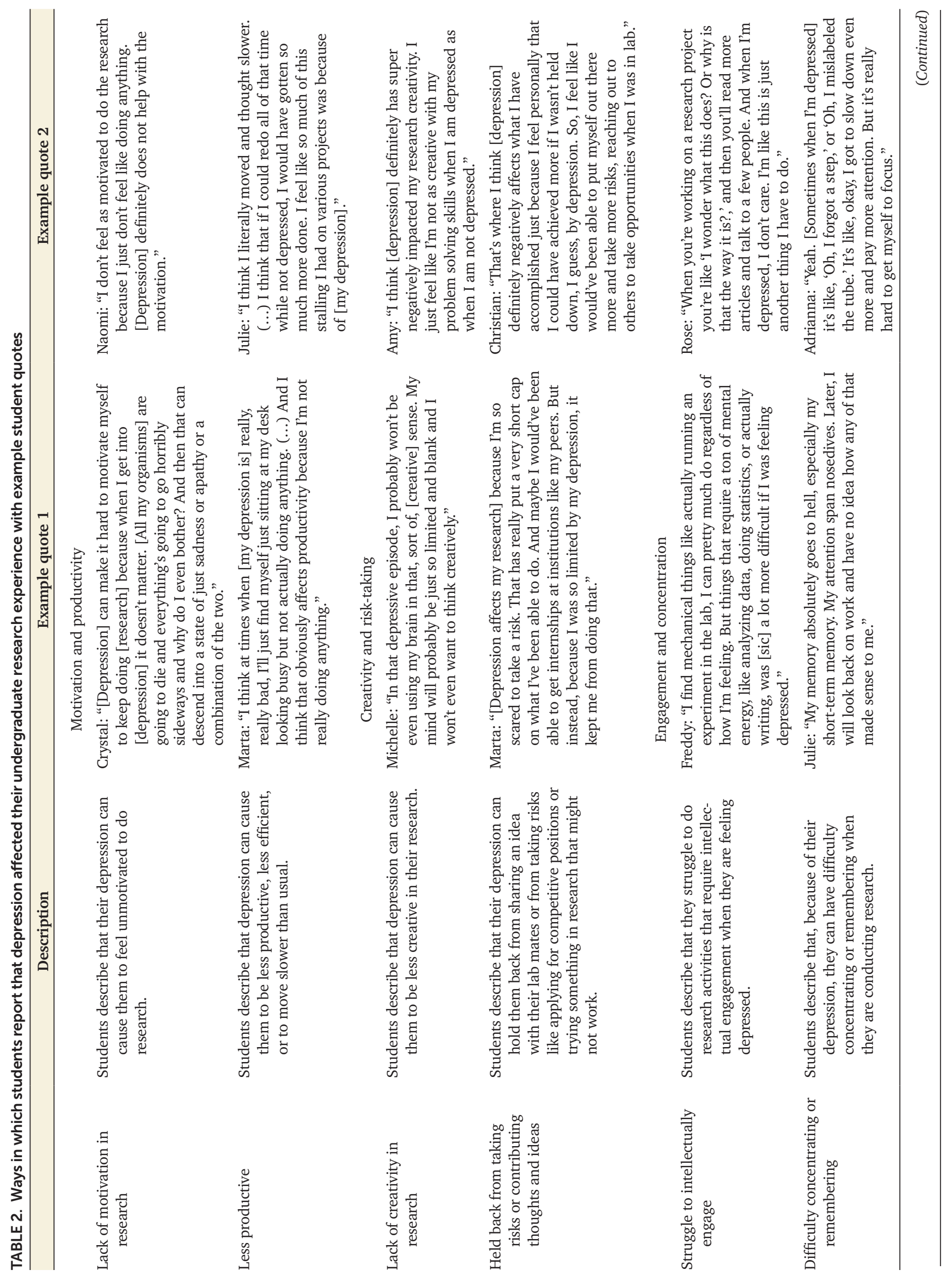




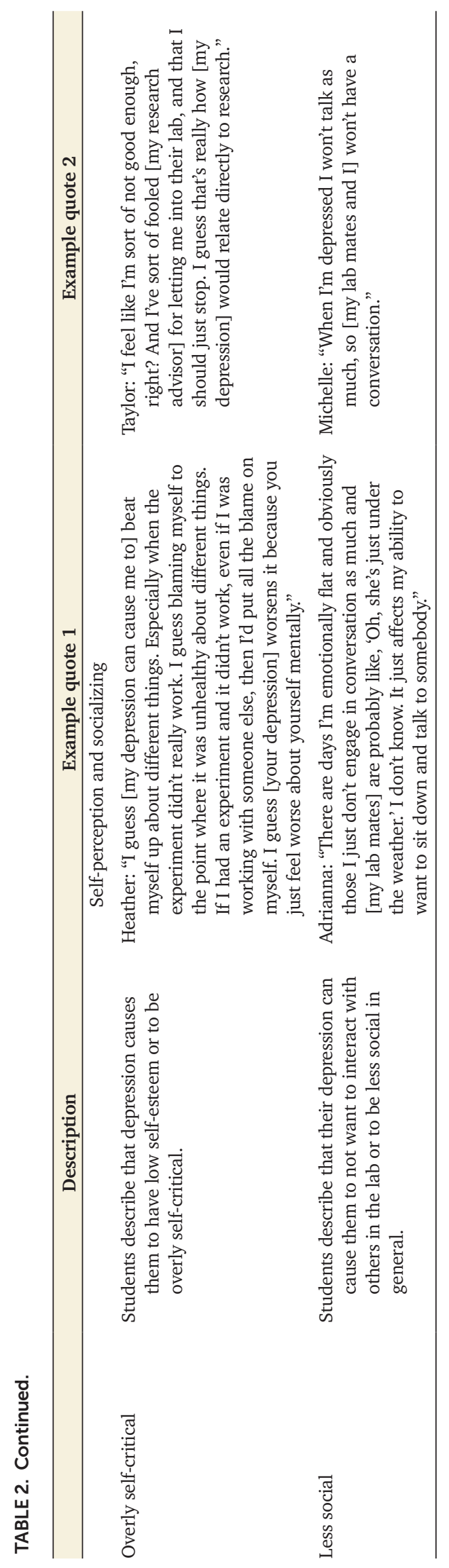

of motivation or because they felt less creative, which hindered the research process. Additionally, students highlighted that they were sometimes less productive because their depression sometimes caused them to struggle to engage intellectually with their research or caused them to have difficulty remembering or concentrating; students described that they could do mundane or routine tasks when they felt depressed, but that they had difficulty with more complex and intellectually demanding tasks. However, students sometimes described that even mundane tasks could be difficult when they were required to remember specific steps; for example, some students struggled recalling a protocol from memory when their depression was particularly severe. Additionally, students noted that their depression made them more self-conscious, which sometimes held them back from sharing research ideas with their mentors or from taking risks such as applying to competitive programs. In addition to being self-conscious, students highlighted that their depression caused them to be overly self-critical, and some described experiencing imposter phenomenon (Clance and Imes, 1978) or feeling like they were not talented enough to be in research and were accepted into a lab by a fluke or through luck. Finally, students described that depression often made them feel less social, and they struggled to socially engage with other members of the lab when they were feeling down.

\section{The Effect of Undergraduate Research Experiences on Student Depression}

We also wanted to explore how research impacted students' feelings of depression. Undergraduates described how research both positively and negatively affected their depression. In the following sections, we present aspects of undergraduate research and examine how each positively and/or negatively affected students' depression using embedded student quotes to highlight the relationships between related ideas.

Lab Environment: Relationships with Others in the Lab. Some aspects of the lab environment, which we define as students' physical, social, or psychological research space, could be particularly beneficial for students with depression.

Specifically, undergraduate researchers perceived that comfortable and positive social interactions with others in the lab helped their depression. Students acknowledged how beneficial their relationships with graduate students and postdocs could be.

Marta: "I think always checking in on undergrads is important. It's really easy [for us] to go a whole day without talking to anybody in the lab. But our grad students are like 'Hey, what's up? How's school? What's going on?' (...) What helps me the most is having that strong support system. Sometimes just talking makes you feel better, but also having people that believe in you can really help you get out of that negative spiral. I think that can really help with depression."

Kelley: "I know that anytime I need to talk to [my postdoc mentors] about something they're always there for me. Over time we've developed a relationship where I know that outside of work and outside of the lab if I did want to talk to them about something I could talk to them. Even just talking to someone about hobbies and having that relationship alone is really helpful [for depression]." 
In addition to highlighting the importance of developing relationships with graduate students or postdocs in the lab, students described that forming relationships with other undergraduates in the lab also helped their depression. Particularly, students described that other undergraduate researchers often validated their feelings about research, which in turn helped them realize that what they are thinking or feeling is normal, which tended to alleviate their negative thoughts. Interestingly, other undergraduates experiencing the same issues could sometimes help buffer them from perceiving that a mentor did not like them or that they were uniquely bad at research. In this article, we use the term "mentor" to refer to anyone who students referred to in the interviews as being their mentors or managing their research experiences; this includes graduate students, postdoctoral scholars, lab managers, and primary investigators (PIs).

\begin{abstract}
Abby: "One of my best friends is in the lab with me. A lot of that friendship just comes from complaining about our stress with the lab and our annoyance with people in the lab. Like when we both agree like, 'Yeah, the grad students were really off today, it wasn't us,' that helps. 'It wasn't me, it wasn't my fault that we were having a rough day in lab; it was the grad students.' Just being able to realize, 'Hey, this isn't all caused by us,' you know? (...) We understand the stresses in the lab. We understand the details of what each other are doing in the lab, so when something doesn't work out, we understand that it took them like eight hours to do that and it didn't work. We provide empathy on a different level."
\end{abstract}

Meleana: "It's great to have solidarity in being confused about something, and it's just that is a form of validation for me too. When we leave a lab meeting and I look at [another undergrad] I'm like, 'Did you understand anything that they were just saying?' And they're like, 'Oh, no.' (...) It's just really validating to hear from the other undergrads that we all seem to be struggling with the same things."

Developing positive relationships with faculty mentors or PIs also helped alleviate some students' depressive feelings, particularly when PIs shared their own struggles with students. This also seemed to normalize students' concerns about their own experiences.

Alexandra: "[Talking with my PI] is helpful because he would talk about his struggles, and what he faced. A lot of it was very similar to my struggles. For example, he would say, 'Oh, yeah, I failed this exam that I studied so hard for. I failed the GRE and I paid so much money to prepare for it.' It just makes [my depression] better, like okay, this is normal for students to go through this. It's not an out of this world thing where if you fail, you're a failure and you can't move on from it."

Students' relationships with others in the lab did not always positively impact their depression. Students described instances when the negative moods of the graduate students and PIs would often set the tone of the lab, which in turn worsened the mood of the undergraduate researchers.

Abby: "Sometimes [the grad students] are not in a good mood. The entire vibe of the lab is just off, and if you make a joke and it hits somebody wrong, they get all mad. It really depends on the grad students and the leadership and the mood that they're in."

Interviewer: "How does it affect your depression when the grad students are in a bad mood?"

Abby: "It definitely makes me feel worse. It feels like, again, that I really shouldn't go ask them for help because they're just not in the mood to help out. It makes me have more pressure on myself, and I have deadlines I need to meet, but I have a question for them, but they're in a bad mood so I can't ask. That's another day wasted for me and it just puts more stress, which just adds to the depression."

Additionally, some students described even more concerning behavior from research mentors, which negatively affected their depression.

Julie: "I had a primary investigator who is notorious in the department for screaming at people, being emotionally abusive, unreasonable, et cetera. (...) [He was] kind of harassing people, demeaning them, lying to them, et cetera, et cetera. (...) Being yelled at and constantly demeaned and harassed at all hours of the day and night, that was probably pretty bad for me."

While the relationships between undergraduates and graduate, postdoc, and faculty mentors seemed to either alleviate or worsen students' depressive symptoms, depending on the quality of the relationship, students in this study exclusively described their relationships with other undergraduates as positive for their depression. However, students did note that undergraduate research puts some of the best and brightest undergraduates in the same environment, which can result in students comparing themselves with their peers. Students described that this comparison would often lead them to feel badly about themselves, even though they would describe their personal relationship with a person to be good.

Meleana: "In just the research field in general, just feeling like I don't really measure up to the people around me [can affect my depression]. A lot of the times it's the beginning of a little spiral, mental spiral. There are some past undergrads that are talked about as they're on this pedestal of being the ideal undergrads and that they were just so smart and contributed so much to the lab. I can never stop myself from wondering like, 'Oh, I wonder if I'm having a contribution to the lab that's similar or if I'm just another one of the undergrads that does the bare minimum and passes through and is just there."

Natasha: "But, on the other hand, [having another undergrad in the lab] also reminded me constantly that some people are invested in this and meant to do this and it's not me. And that some people know a lot more than I do and will go further in this than I will."

While students primarily expressed that their relationships with others in the lab affected their depression, some students explained that they struggled most with depression when the lab was empty; they described that they did not like being alone in the lab, because a lack of stimulation allowed their minds to be filled with negative thoughts. 
Mia: “Those late nights definitely didn't help [my depression]. I am alone, in the entire building. I'm left alone to think about my thoughts more, so not distracted by talking to people or interacting with people. I think more about how I'm feeling and the lack of progress I'm making, and the hopelessness I'm feeling. That kind of dragged things on, and I guess deepened my depression."

Freddy: "Often times when I go to my office in the evening, that is when I would [sic] be prone to be more depressed. It's being alone. I think about myself or mistakes or trying to correct mistakes or whatever's going on in my life at the time. I become very introspective. I think I'm way too self-evaluating, way too self-deprecating and it's when I'm alone when those things are really, really triggered. When I'm talking with somebody else, I forget about those things."

In sum, students with depression highlighted that a lab environment full of positive and encouraging individuals was helpful for their depression, whereas isolating or competitive environments and negative interactions with others often resulted in more depressive feelings.

Doing Science: Experiencing Failure in Research, Getting Help, Receiving Feedback, Time Demands, and Important Contributions. In addition to the lab environment, students also described that the process of doing science could affect their depression. Specifically, students explained that a large contributor to their depression was experiencing failure in research.

Interviewer: "Considering your experience in undergraduate research, what tends to trigger your feelings of depression?"

Heather: "Probably just not getting things right. Having to do an experiment over and over again. You don't get the results you want. (...) The work is pretty meticulous and it's frustrating when I do all this work, I do a whole experiment, and then I don't get any results that I can use. That can be really frustrating. It adds to the stress. (...) It's hard because you did all this other stuff before so you can plan for the research, and then something happens and all the stuff you did was worthless basically."

Julie: "I felt very negatively about myself [when a project failed] and pretty panicked whenever something didn't work because I felt like it was a direct reflection on my effort and/or intelligence, and then it was a big glaring personal failure."

Students explained that their depression related to failing in research was exacerbated if they felt as though they could not seek help from their research mentors. Perceived insufficient mentor guidance has been shown to be a factor influencing student intention to leave undergraduate research (Cooper et al., 2019c). Sometimes students talked about their research mentors being unavailable or unapproachable.

Michelle: "It just feels like [the graduate students] are not approachable. I feel like I can't approach them to ask for their understanding in a certain situation. It makes [my depression] worse because I feel like I'm stuck, and that I'm being limited, and like there's nothing I can do. So then I kind of feel like it's my fault that I can't do anything."
Other times, students described that they did not seek help in fear that they would be negatively evaluated in research, which is a fear of being judged by others (Watson and Friend, 1969; Weeks et al., 2005; Cooper et al., 2018). That is, students fear that their mentor would think negatively about them or judge them if they were to ask questions that their mentor thought they should know the answer to.

Meleana: "I would say [my depression] tends to come out more in being more reserved in asking questions because I think that comes more like a fear-based thing where I'm like, 'Oh, I don't feel like I'm good enough and so I don't want to ask these questions because then my mentors will, I don't know, think that I'm dumb or something."'

Conversely, students described that mentors who were willing to help them alleviated their depressive feelings.

Crystal: "Yeah [my grad student] is always like, 'Hey, I can check in on things in the lab because you're allowed to ask me for that, you're not totally alone in this,' because he knows that I tend to take on all this responsibility and I don't always know how to ask for help. He's like, 'You know, this is my lab too and I am here to help you as well,' and just reminds me that I'm not shouldering this burden by myself."

Ashlyn: "The graduate student who I work with is very kind and has a lot of patience and he really understands a lot of things and provides simple explanations. He does remind me about things and he will keep on me about certain tasks that I need to do in an understanding way, and it's just because he's patient and he listens."

In addition to experiencing failure in science, students described that making mistakes when doing science also negatively affected their depression.

\begin{abstract}
Abby: "I guess not making mistakes on experiments [is important in avoiding my depression]. Not necessarily that your experiment didn't turn out to produce the data that you wanted, but just adding the wrong enzyme or messing something up like that. It's like, 'Oh, man,' you know? You can get really down on yourself about that because it can be embarrassing."
\end{abstract}

Commonly, students described that the potential for making mistakes increased their stress and anxiety regarding research; however, they explained that how other people responded to a potential mistake was what ultimately affected their depression.

Briana: "Sometimes if I made a mistake in correctly identifying an eye color [of a fly], [my PI] would just ridicule me in front of the other students. He corrected me but his method of correcting was very discouraging because it was a ridicule. It made the others laugh and I didn't like that."

Julie: "[My PI] explicitly [asked] if I had the dedication for science. A lot of times he said I had terrible judgment. A lot of times he said I couldn't be trusted. Once I went to a conference with him, and, unfortunately, in front of another professor, he 
called me a klutz several times and there was another comment about how I never learn from my mistakes."

When students did do things correctly, they described how important it could be for them to receive praise from their mentors. They explained that hearing praise and validation can be particularly helpful for students with depression, because their thoughts are often very negative and/or because they have low self-esteem.

Crystal: "[Something that helps my depression is] I have text messages from [my graduate student mentor] thanking me [and another undergraduate researcher] for all of the work that we've put in, that he would not be able to be as on track to finish as he is if he didn't have our help."

Interviewer: "Why is hearing praise from your mentor helpful?"

Crystal: "Because a lot of my depression focuses on everybody secretly hates you, nobody likes you, you're going to die alone. So having that validation [from my graduate mentor] is important, because it flies in the face of what my depression tells me."

Brian: "It reminds you that you exist outside of this negative world that you've created for yourself, and people don't see you how you see yourself sometimes."

Students also highlighted how research could be overwhelming, which negatively affected their depression. Particularly, students described that research demanded a lot of their time and that their mentors did not always seem to be aware that they were juggling school and other commitments in addition to their research. This stress exacerbated their depression.

Rose: "I feel like sometimes [my grad mentors] are not very understanding because grad students don't take as many classes as [undergrads] do. I think sometimes they don't understand when I say I can't come in at all this week because I have finals and they're like, 'Why though?"'

Abby: "I just think being more understanding of student life would be great. We have classes as well as the lab, and classes are the priority. They forget what it's like to be a student. You feel like they don't understand and they could never understand when you say like, 'I have three exams this week,' and they're like, 'I don't care. You need to finish this."'

Conversely, some students reported that their research labs were very understanding of students' schedules. Interestingly, these students talked most about how helpful it was to be able to take a mental health day and not do research on days when they felt down or depressed.

Marta: "My lab tech is very open, so she'll tell us, 'I can't come in today. I have to take a mental health day.' So she's a really big advocate for that. And I think I won't personally tell her that I'm taking a mental health day, but I'll say, 'I can't come in today, but I'll come in Friday and do those extra hours.' And she's like, 'OK great, I'll see you then.' And it makes me feel good, because it helps me take care of myself first and then I can take care of everything else I need to do, which is amazing."

Meleana: "Knowing that [my mentors] would be flexible if I told them that I'm crazy busy and can't come into work nearly as much this week [helps my depression]. There is flexibility in allowing me to then care for myself."

Interviewer: "Why is the flexibility helpful given the depression?"

Meleana: "Because sometimes for me things just take a little bit longer when I'm feeling down. I'm just less efficient to be honest, and so it's helpful if I feel like I can only go into work for 10 hours in a week. It declutters my brain a little bit to not have to worry about all the things I have to do in work in addition the things that I need to do for school or clubs, or family or whatever."

Despite the demanding nature of research, a subset of students highlighted that their research and research lab provided a sense of stability or familiarity that distracted them from their depression.

Freddy: "I'll [do research] to run away from those [depressive] feelings or whatever. (...) I find sadly, I hate to admit it, but I do kind of run to [my lab]. I throw myself into work to distract myself from the feelings of depression and sadness."

Rose: "When you're sad or when you're stressed you want to go to things you're familiar with. So because lab has always been in my life, it's this thing where it's going to be there for me I guess. It's like a good book that you always go back to and it's familiar and it makes you feel good. So that's how lab is. It's not like the greatest thing in the world but it's something that I'm used to, which is what I feel like a lot of people need when they're sad and life is not going well."

Many students also explained that research positively affects their depression because they perceive their research contribution to be important.

Ashlyn: "I feel like I'm dedicating myself to something that's worthy and something that I believe in. It's really important because it contextualizes those times when I am feeling depressed. It's like, no, I do have these better things that I'm working on. Even when I don't like myself and I don't like who I am, which is again, depression brain, I can at least say, 'Well, I have all these other people relying on me in research and in this area and that's super important."'

Jessica: "I mean, it just felt like the work that I was doing had meaning and when I feel like what I'm doing is actually going to contribute to the world, that usually really helps with [depression] because it's like not every day you can feel like you're doing something impactful."

In sum, students highlighted that experiencing failure in research and making mistakes negatively contributed to depression, especially when help was unavailable or research mentors had a negative reaction. Additionally, students acknowledged 
that the research could be time-consuming, but that research mentors who were flexible helped assuage depressive feelings that were associated with feeling overwhelmed. Finally, research helped some students' depression, because it felt familiar, provided a distraction from depression, and reminded students that they were contributing to a greater cause.

\section{DISCUSSION}

We believe that creating more inclusive research environments for students with depression is an important step toward broadening participation in science, not only to ensure that we are not discouraging students with depression from persisting in science, but also because depression has been shown to disproportionately affect underserved and underrepresented groups in science (Turner and Noh, 1988; Eisenberg et al., 2007; Jenkins et al., 2013; American College Health Association, 2018). We initially hypothesized that three features of undergraduate research-research mentors, the lab environment, and failuremay have the potential to exacerbate student depression. We found this to be true; students highlighted that their relationships with their mentors as well as the overall lab environment could negatively affect their depression, but could also positively affect their research experiences. Students also noted that they struggled with failure, which is likely true of most students, but is known to be particularly difficult for students with depression (Elliott et al., 1997). We expand upon our findings by integrating literature on depression with the information that students provided in the interviews about how research mentors can best support students. We provide a set of evidence-based recommendations focused on mentoring, the lab environment, and failure for research mentors wanting to create more inclusive research environments for students with depression. Notably, only the first recommendation is specific to students with depression; the others reflect recommendations that have previously been described as "best practices" for research mentors (NASEM, 2017, 2019; Sorkness et al. , 2017) and likely would benefit most students. However, we examine how these recommendations may be particularly important for students with depression. As we hypothesized, these recommendations directly address three aspects of research: mentors, lab environment, and failure. A caveat of these recommendations is that more research needs to be done to explore the experiences of students with depression and how these practices actually impact students with depression, but our national sample of undergraduate researchers with depression can provide an initial starting point for a discussion about how to improve research experiences for these students.

\section{Recommendations to Make Undergraduate Research Experiences More Inclusive for Students with Depression} Recognize Student Depression as a Valid Illness. Allow students with depression to take time off of research by simply saying that they are sick and provide appropriate time for students to recover from depressive episodes. Also, make an effort to destigmatize mental health issues.

Undergraduate researchers described both psychological and physical symptoms that manifested as a result of their depression and highlighted how such symptoms prevented them from performing to their full potential in undergraduate research. For example, students described how their depression would cause them to feel unmotivated, which would often neg- atively affect their research productivity. In cases in which students were motivated enough to come in and do their research, they described having difficulty concentrating or engaging in the work. Further, when doing research, students felt less creative and less willing to take risks, which may alter the quality of their work. Students also sometimes struggled to socialize in the lab. They described feeling less social and feeling overly self-critical. In sum, students described that, when they experienced a depressive episode, they were not able to perform to the best of their ability, and it sometimes took a toll on them to try to act like nothing was wrong, when they were internally struggling with depression. We recommend that research mentors treat depression like any other physical illness; allowing students the chance to recover when they are experiencing a depressive episode can be extremely important to students and can allow them to maximize their productivity upon returning to research (Judd et al., 2000). Students explained that if they are not able to take the time to focus on recovering during a depressive episode, then they typically continue to struggle with depression, which negatively affects their research. This sentiment is echoed by researchers in psychiatry who have found that patients who do not fully recover from a depressive episode are more likely to relapse and to experience chronic depression (Judd et al., 2000). Students described not doing tasks or not showing up to research because of their depression but struggling with how to share that information with their research mentors. Often, students would not say anything, which caused them anxiety because they were worried about what others in the lab would say to them when they returned. Admittedly, many students understood why this behavior would cause their research mentors to be angry or frustrated, but they weighed the consequences of their research mentors' displeasure against the consequences of revealing their depression and decided it was not worth admitting to being depressed. This aligns with literature that suggests that when individuals have concealable stigmatized identities, or identities that can be hidden and that carry negative stereotypes, such as depression, they will often keep them concealed to avoid negative judgment or criticism (Link and Phelan, 2001; Quinn and Earnshaw, 2011; Jones and King, 2014; Cooper and Brownell, 2016; Cooper et al., 2019b; Cooper et al., unpublished data). Therefore, it is important for research mentors to be explicit with students that 1 ) they recognize mental illness as a valid sickness and 2) that students with mental illness can simply explain that they are sick if they need to take time off. This may be useful to overtly state on a research website or in a research syllabus, contract, or agreement if mentors use such documents when mentoring undergraduates in their lab. Further, research mentors can purposefully work to destigmatize mental health issues by explicitly stating that struggling with mental health issues, such as depression and anxiety, is common. While we do not recommend that mentors ask students directly about depression, because this can force students to share when they are not comfortable sharing, we do recommend providing opportunities for students to reveal their depression (Chaudoir and Fisher, 2010). Mentors can regularly check in with students about how they're doing, and talk openly about the importance of mental health, which may increase the chance that students may feel comfortable revealing their depression (Chaudoir and Quinn, 2010; Cooper et al., unpublished data). 
Foster a Positive Lab Environment. Encourage positivity in the research lab, promote working in shared spaces to enhance social support among lab members, and alleviate competition among undergraduates.

Students in this study highlighted that the "leadership" of the lab, meaning graduate students, postdocs, lab managers, and PIs, were often responsible for establishing the tone of the lab; that is, if they were in a bad mood it would trickle down and negatively affect the moods of the undergraduates. Explicitly reminding lab leadership that their moods can both positively and negatively affect undergraduates may be important in establishing a positive lab environment. Further, students highlighted how they were most likely to experience negative thoughts when they were alone in the lab. Therefore, it may be helpful to encourage all lab members to work in a shared space to enhance social interactions among students and to maximize the likelihood that undergraduates have access to help when needed. A review of 51 studies in psychiatry supported our undergraduate researchers' perceptions that social relationships positively impacted their depression; the study found that perceived emotional support (e.g., someone available to listen or give advice), perceived instrumental support (e.g., someone available to help with tasks), and large diverse social networks (e.g., being socially connected to a large number of people) were significantly protective against depression (Santini et al., 2015). Additionally, despite forming positive relationships with other undergraduates in the lab, many undergraduate researchers admitted to constantly comparing themselves with other undergraduates, which led them to feel inferior, negatively affecting their depression. Some students talked about mentors favoring current undergraduates or talking positively about past undergraduates, which further exacerbated their feelings of inferiority. A recent study of students in undergraduate research experiences highlighted that inequitable distribution of praise to undergraduates can create negative perceptions of lab environments for students (Cooper et al., 2019). Further, the psychology literature has demonstrated that when people feel insecure in their social environments, it can cause them to focus on a hierarchical view of themselves and others, which can foster feelings of inferiority and increase their vulnerability to depression (Gilbert et al., 2009). Thus, we recommend that mentors be conscious of their behaviors so that they do not unintentionally promote competition among undergraduates or express favoritism toward current or past undergraduates. Praise is likely best used without comparison with others and not done in a public way, although more research on the impact of praise on undergraduate researchers needs to be done. While significant research has been done on mentoring and mentoring relationships in the context of undergraduate research (Byars-Winston et al., 2015; Aikens et al., 2017; Estrada et al., 2018; Limeri et al., 2019; NASEM, 2019), much less has been done on the influence of the lab environment broadly and how people in nonmentoring roles can influence one another. Yet, this study indicates the potential influence of many different members of the lab, not only their mentors, on students with depression.

Develop More Personal Relationships with Undergraduate Researchers and Provide Sufficient Guidance. Make an effort to establish more personal relationships with undergraduates and ensure that they perceive that they have access to sufficient help and guidance with regard to their research.
When we asked students explicitly how research mentors could help create more inclusive environments for undergraduate researchers with depression, students overwhelmingly said that building mentor-student relationships would be extremely helpful. Students suggested that mentors could get to know students on a more personal level by asking about their career interests or interests outside of academia. Students also remarked that establishing a more personal relationship could help build the trust needed in order for undergraduates to confide in their research mentors about their depression, which they perceived would strengthen their relationships further because they could be honest about when they were not feeling well or their mentors might even "check in" with them in times where they were acting differently than normal. This aligns with studies showing that undergraduates are most likely to reveal a stigmatized identity, such as depression, when they form a close relationship with someone (Chaudoir and Quinn, 2010). Many were intimidated to ask for research-related help from their mentors and expressed that they wished they had established a better relationship so that they would feel more comfortable. Therefore, we recommend that research mentors try to establish relationships with their undergraduates and explicitly invite them to ask questions or seek help when needed. These recommendations are supported by national recommendations for mentoring (NASEM, 2019) and by literature that demonstrates that both social support (listening and talking with students) and instrumental support (providing students with help) have been shown to be protective against depression (Santini et al., 2015).

Treat Undergraduates with Respect and Remember to Praise Them. Avoid providing harsh criticism and remember to praise undergraduates. Students with depression often have low self-esteem and are especially self-critical. Therefore, praise can help calibrate their overly negative self-perceptions.

Students in this study described that receiving criticism from others, especially harsh criticism, was particularly difficult for them given their depression. Multiple studies have demonstrated that people with depression can have an abnormal or maladaptive response to negative feedback; scientists hypothesize that perceived failure on a particular task can trigger failure-related thoughts that interfere with subsequent performance (Eshel and Roiser, 2010). Thus, it is important for research mentors to remember to make sure to avoid unnecessarily harsh criticisms that make students feel like they have failed (more about failure is described in the next recommendation). Further, students with depression often have low self-esteem or low "personal judgment of the worthiness that is expressed in the attitudes the individual holds towards oneself" (Heatherton et al., 2003, p. 220; Sowislo and Orth, 2013). Specifically, a meta-analysis of longitudinal studies found that low self-esteem is predictive of depression (Sowislo and Orth, 2013), and depression has also been shown to be highly related to self-criticism (Luyten et al., 2007). Indeed, nearly all of the students in our study described thinking that they are "not good enough," "worthless," or "inadequate," which is consistent with literature showing that people with depression are self-critical (Blatt et al., 1982; Gilbert et al., 2006) and can be less optimistic of their performance on future tasks and rate their overall performance 
on tasks less favorably than their peers without depression (Cane and Gotlib, 1985). When we asked students what aspects of undergraduate research helped their depression, students described that praise from their mentors was especially impactful, because they thought so poorly of themselves and they needed to hear something positive from someone else in order to believe it could be true. Praise has been highlighted as an important aspect of mentoring in research for many years (Ashford, 1996; Gelso and Lent, 2000; Brown et al., 2009) and may be particularly important for students with depression. In fact, praise has been shown to enhance individuals' motivation and subsequent productivity (Hancock, 2002; Henderlong and Lepper, 2002), factors highlighted by students as negatively affecting their depression. However, something to keep in mind is that a student with depression and a student without depression may process praise differently. For a student with depression, a small comment that praises the student's work may not be sufficient for the student to process that comment as praise. People with depression are hyposensitive to reward or have reward-processing deficits (Eshel and Roiser, 2010); therefore, praise may affect students without depression more positively than it would affect students with depression. Research mentors should be mindful that students with depression often have a negative view of themselves, and while students report that praise is extremely important, they may have trouble processing such positive feedback.

Normalize Failure and Be Explicit about the Importance of Research Contributions. Explicitly remind students that experiencing failure is expected in research. Also explain to students how their individual work relates to the overall project so that they can understand how their contributions are important. It can also be helpful to explain to students why the research project as a whole is important in the context of the greater scientific community.

Experiencing failure has been thought to be a potentially important aspect of undergraduate research, because it may provide students with the potential to develop integral scientific skills such as the ability to navigate challenges and persevere (Laursen et al., 2010; Gin et al., 2018; Henry et al., 2019). However, in the interviews, students described that when their science experiments failed, it was particularly tough for their depression. Students' negative reaction to experiencing failure in research is unsurprising, given recent literature that has predicted that students may be inadequately prepared to approach failure in science (Henry et al., 2019). However, the literature suggests that students with depression may find experiencing failure in research to be especially difficult (Elliott et al., 1997; Mongrain and Blackburn, 2005; Jones et al., 2009). One potential hypothesis is that students with depression may be more likely to have fixed mindsets or more likely to believe that their intelligence and capacity for specific abilities are unchangeable traits (Schleider and Weisz, 2018); students with a fixed mindset have been hypothesized to have particularly negative responses to experiencing failure in research, because they are prone to quitting easily in the face of challenges and becoming defensive when criticized (Forsythe and Johnson, 2017; Dweck, 2008). A study of life sciences undergraduates enrolled in CUREs identified three strategies of students who adopted adaptive coping mechanisms, or mechanisms that help an indi- vidual maintain well-being and/or move beyond the stressor when faced with failure in undergraduate research: 1) problem solving or engaging in strategic planning and decision making, 2) support seeking or finding comfort and help with research, and 3) cognitive restructuring or reframing a problem from negative to positive and engaging in self encouragement (Gin et al., 2018). We recommend that, when undergraduates experience failure in science, their mentors be proactive in helping them problem solve, providing help and support, and encouraging them. Students also explained that mentors sharing their own struggles as undergraduate and graduate students was helpful, because it normalized failure. Sharing personal failures in research has been recommended as an important way to provide students with psychosocial support during research (NASEM, 2019). We also suggest that research mentors take time to explain to students why their tasks in the lab, no matter how small, contribute to the greater research project (Cooper et al., 2019a). Additionally, it is important to make sure that students can explain how the research project as a whole is contributing to the scientific community (Gin et al., 2018). Students highlighted that contributing to something important was really helpful for their depression, which is unsurprising, given that studies have shown that meaning in life or people's comprehension of their life experiences along with a sense of overarching purpose one is working toward has been shown to be inversely related to depression (Steger, 2013).

\section{Limitations and Future Directions}

This work was a qualitative interview study intended to document a previously unstudied phenomenon: depression in the context of undergraduate research experiences. We chose to conduct semistructured interviews rather than a survey because of the need for initial exploration of this area, given the paucity of prior research. A strength of this study is the sampling approach. We recruited a national sample of 35 undergraduates engaged in undergraduate research at 12 different public R1 institutions. Despite our representative sample from R1 institutions, these findings may not be generalizable to students at other types of institutions; lab environments, mentoring structures, and interactions between faculty and undergraduate researchers may be different at other institution types (e.g., private R1 institutions, R2 institutions, master's-granting institutions, primarily undergraduate institutions, and community colleges), so we caution against making generalizations about this work to all undergraduate research experiences. Future work could assess whether students with depression at other types of institutions have similar experiences to students at research-intensive institutions. Additionally, we intentionally did not explore the experiences of students with specific identities owing to our sample size and the small number of students in any particular group (e.g., students of a particular race, students with a graduate mentor as the primary mentor). We intend to conduct future quantitative studies to further explore how students' identities and aspects of their research affect their experiences with depression in undergraduate research.

The students who participated in the study volunteered to be interviewed about their depression; therefore, it is possible that depression is a more salient part of these students' identities and/or that they are more comfortable talking about their depression than the average population of students with 
depression. It is also important to acknowledge the personal nature of the topic and that some students may not have fully shared their experiences (Krumpal, 2013), particularly those experiences that may be emotional or traumatizing (Kahn and Garrison, 2009). Additionally, our sample was skewed toward females (77\%). While females do make up approximately $60 \%$ of students in biology programs on average (Eddy et al., 2014), they are also more likely to report experiencing depression (American College Health Association, 2018; Evans et al., 2018). However, this could be because women have higher rates of depression or because males are less likely to report having depression; clinical bias, or practitioners' subconscious tendencies to overlook male distress, may underestimate depression rates in men (Smith et al., 2018). Further, females are also more likely to volunteer to participate in studies (Porter and Whitcomb, 2005); therefore, many interview studies have disproportionately more females in the data set (e.g., Cooper et al., 2017). If we had been able to interview more male students, we might have identified different findings. Additionally, we limited our sample to life sciences students engaged in undergraduate research at public R1 institutions. It is possible that students in other majors may have different challenges and opportunities for students with depression, as well as different disciplinary stigmas associated with mental health.

\section{CONCLUSION}

In this exploratory interview study, we identified a variety of ways in which depression in undergraduates negatively affected their undergraduate research experiences. Specifically, we found that depression interfered with students' motivation and productivity, creativity and risk-taking, engagement and concentration, and self-perception and socializing. We also identified that research can negatively affect depression in undergraduates. Experiencing failure in research can exacerbate student depression, especially when students do not have access to adequate guidance. Additionally, being alone or having negative interactions with others in the lab worsened students' depression. However, we also found that undergraduate research can positively affect students' depression. Research can provide a familiar space where students can feel as though they are contributing to something meaningful. Additionally, students reported that having access to adequate guidance and a social support network within the research lab also positively affected their depression. We hope that this work can spark conversations about how to make undergraduate research experiences more inclusive of students with depression and that it can stimulate additional research that more broadly explores the experiences of undergraduate researchers with depression.

\section{Important note}

If you or a student experience symptoms of depression and want help, there are resources available to you. Many campuses provide counseling centers equipped to provide students, staff, and faculty with treatment for depression, as well as university-dedicated crisis hotlines. Additionally, there are free 24/7 services such as Crisis Text Line, which allows you to text a trained live crisis counselor (Text "CONNECT" to 741741; Text Depression Hotline, 2019), and phone hotlines such as the National Suicide Prevention Lifeline at 1-800-273-8255 (TALK). You can also learn more about depression and where to find help near you through the Anxiety and Depression Association of American website: https://adaa.org (Anxiety and Depression Association of America, 2019) and the Depression and Biopolar Support Alliance: http://dbsalliance.org (Depression and Biopolar Support Alliance, 2019).

\section{ACKNOWLEDGMENTS}

We are extremely grateful to the undergraduate researchers who shared their thoughts and experiences about depression with us. We acknowledge the ASU LEAP Scholars for helping us create the original survey and Rachel Scott for her helpful feedback on earlier drafts of this article. L.E.G. was supported by a National Science Foundation (NSF) Graduate Fellowship (DGE1311230) and K.M.C. was partially supported by a Howard Hughes Medical Institute (HHMI) Inclusive Excellence grant (no. 11046) and an NSF grant (no. 1644236). Any opinions, findings, conclusions, or recommendations expressed in this material are those of the authors and do not necessarily reflect the views of the NSF or HHMI.

\section{REFERENCES}

Aikens, M. L., Robertson, M. M., Sadselia, S., Watkins, K., Evans, M., Runyon, C. R., ... \& Dolan, E. L. (2017). Race and gender differences in undergraduate research mentoring structures and research outcomes. CBE-Life Sciences Education, 16(2), ar34

Aikens, M. L., Sadselia, S., Watkins, K., Evans, M., Eby, L. T., \& Dolan, E. L. (2016). A social capital perspective on the mentoring of undergraduate life science researchers: An empirical study of undergraduate-postgraduate-faculty triads. CBE-Life Sciences Education, 15(2), ar16.

Aldwin, C., \& Greenberger, E. (1987). Cultural differences in the predictors of depression. American Journal of Community Psychology, 15(6), 789-813.

American Association for the Advancement of Science. (2011). Vision and change in undergraduate biology education: A call to action. Retrieved November 29, 2019, from http://visionandchange.org/files/2013/11/aaas -VISchange-web1113.pdf

American College Health Association. (2018). Undergraduate reference group executive summary, Fall 2018. Retrieved November 29, 2019, from www.acha.org/documents/ncha/NCHA-II_Fall_2018_Reference _Group_Executive_Summary.pdf

American College Health Association. (2019). Retrieved November 29, 2019 from NCHA-II_SPRING_2019_UNDERGRADUATE_REFERENCE_GROUP_ DATA_REPORT.pdf www.acha.org/documents/ncha/NCHA-II_SPRING _2019_UNDERGRADUATE_REFERENCE_GROUP_DATA_REPORT.pdf

American Psychiatric Association. (2013). Diagnostic and statistical manual of mental disorders (5th ed.). Washington, DC: American Psychiatric Publishing.

Aneshensel, C. S., \& Stone, J. D. (1982). Stress and depression: A test of the buffering model of social support. Archives of General Psychiatry, 39(12), 1392-1396.

Anxiety and Depression Association of America. (2019). Home page. Retrieved November 29, 2019, from https://adaa.org

Armbruster, P., Patel, M., Johnson, E., \& Weiss, M. (2009). Active learning and student-centered pedagogy improve student attitudes and performance in introductory biology. CBE-Life Sciences Education, 8(3), 203-213.

Ashford, S. J. (1996). Working with doctoral students: Rhythms of Academic Life: Personal Accounts of Careers in Academia. In Front, P. J., \& Taylor, M. S. (Eds.), Rhythms of Academic Life: Personal Accounts of Careers in Academia (pp. 153-158). Thousand Oaks, CA: Sage.

Auchincloss, L. C., Laursen, S. L., Branchaw, J. L., Eagan, K., Graham, M., Hanauer, D. I., ... \& Rowland, S. (2014). Assessment of course-based undergraduate research experiences: A meeting report. CBE-Life Sciences Education, 13(1), 29-40

Barak, M. E. M., Levin, A., Nissly, J. A., \& Lane, C. J. (2006). Why do they leave? Modeling child welfare workers' turnover intentions. Children and Youth Services Review, 28(5), 548-577. 
Bauer, K. W., \& Bennett, J. S. (2003). Alumni perceptions used to assess undergraduate research experience. Journal of Higher Education, 74(2), 210-230.

Birks, M., \& Mills, J. (2015). Grounded theory: A practical guide. Thousand Oaks, CA: Sage.

Blatt, S. J., Quinlan, D. M., Chevron, E. S., McDonald, C., \& Zuroff, D. (1982) Dependency and self-criticism: Psychological dimensions of depression. Journal of Consulting and Clinical Psychology, 50(1), 113.

Brown, R. T., Daly, B. P., \& Leong, F. T. (2009). Mentoring in research: A developmental approach. Professional Psychology: Research and Practice, 40(3), 306.

Brownell, S. E., Hekmat-Scafe, D. S., Singla, V., Seawell, P. C., Imam, J. F. C., Eddy, S. L., ... \& Cyert, M. S. (2015). A high-enrollment course-based undergraduate research experience improves student conceptions of scientific thinking and ability to interpret data. CBE-Life Sciences Education, 14(2), ar21.

Brownell, S. E., \& Kloser, M. J. (2015). Toward a conceptual framework for measuring the effectiveness of course-based undergraduate research experiences in undergraduate biology. Studies in Higher Education, 40(3), 525-544

Byars-Winston, A. M., Branchaw, J., Pfund, C., Leverett, P., \& Newton, J. (2015). Culturally diverse undergraduate researchers' academic outcomes and perceptions of their research mentoring relationships. International Journal of Science Education, 37(15), 2533-2554

Cane, D. B., \& Gotlib, I. H. (1985). Depression and the effects of positive and negative feedback on expectations, evaluations, and performance. Cognitive Therapy and Research, 9(2), 145-160.

Ceci, S. J., \& Williams, W. M. (2010). Sex differences in math-intensive fields. Current Directions in Psychological Science, 19(5), 275-279.

Center for Collegiate Mental Health. (2017). Center for Collegiate Mental Health 2017 Annual Report. State College, PA: Penn State Universit.

Charmaz, K. (2006). Constructing grounded theory: A practical guide through qualitative research. Thousand Oaks, CA: Sage.

Chaudoir, S. R., \& Fisher, J. D. (2010). The disclosure processes model: Understanding disclosure decision making and postdisclosure outcomes among people living with a concealable stigmatized identity. Psychological Bulletin, 136(2), 236

Chaudoir, S. R., \& Quinn, D. M. (2010). Revealing concealable stigmatized identities: The impact of disclosure motivations and positive first-disclosure experiences on fear of disclosure and well-being. Journal of Social Issues, 66(3), 570-584.

Clance, P. R., \& Imes, S. A. (1978). The imposter phenomenon in high achieving women: Dynamics and therapeutic intervention. Psychotherapy: Theory, Research \& Practice, 15(3), 241

Cooper, K. M., Ashley, M., \& Brownell, S. E. (2017). A bridge to active learning: A summer bridge program helps students maximize their active-learning experiences and the active-learning experiences of others. CBE-Life Sciences Education, 16(1), ar17.

Cooper, K. M., Blattman, J. N., Hendrix, T., \& Brownell, S. E. (2019a). The impact of broadly relevant novel discoveries on student project ownership in a traditional lab course turned CURE. CBE-Life Sciences Education, 18(4), ar57.

Cooper, K. M., \& Brownell, S. E. (2016). Coming out in class: Challenges and benefits of active learning in a biology classroom for LGBTQIA students. CBE-Life Sciences Education, 15(3), ar37. https://doi.org/10.1187/ cbe.16-01-0074

Cooper, K. M., Brownell, S. E., \& Gormally, C. C. (2019b). Coming out to the class: Identifying factors that influence college biology instructor decisions about whether to reveal their LGBQ identity in class. Journal of Women and Minorities in Science and Engineering, 25(3).

Cooper, K. M., Downing, V. R., \& Brownell, S. E. (2018). The influence of active learning practices on student anxiety in large-enrollment college science classrooms. International Journal of STEM Education, 5(1), 23.

Cooper, K. M., Gin, L. E., Akeeh, B., Clark, C. E., Hunter, J. S., Roderick, T. B., ... \& Brownell, S. E. (2019c). Factors that predict life sciences student persistence in undergraduate research experiences. PLOS ONE, 14(8). https://doi.org/10.1371/journal.pone.0220186

Cooper, K. M., Gin, L. E., \& Brownell, S. E. (2019d). Diagnosing differences in what introductory biology students in a fully online and an in-person biology degree program know and do regarding medical school admission. Advances in Physiology Education, 43(2), 221-232.

Cooper, K. M., Gin, L. E., \& Brownell, S. E. (In press). Depression as a concealable stigmatized identity: What influences whether students conceal or reveal their depression in undergraduate research experiences? International Journal of STEM Education, (in press).

Depression and Biopolar Support Alliance. (2019). Home page. Retrieved November 28, 2019, from www.dbsalliance.org

Deroma, V. M., Leach, J. B., \& Leverett, J. P. (2009). The relationship between depression and college academic performance. College Student Journal, 43(2), 325-335.

Dweck, C. S. (2008). Mindset: The new psychology of success. New York, NY Random House Digital.

Dyson, R., \& Renk, K. (2006). Freshmen adaptation to university life: Depressive symptoms, stress, and coping. Journal of Clinical Psychology, 62(10), 1231-1244

Eddy, S. L., Brownell, S. E., \& Wenderoth, M. P. (2014). Gender gaps in achievement and participation in multiple introductory biology classrooms. CBE-Life Sciences Education, 13(3), 478-492. https://doi.org/10.1187/ cbe.13-10-0204

Eisenberg, D., Gollust, S. E., Golberstein, E., \& Hefner, J. L. (2007). Prevalence and correlates of depression, anxiety, and suicidality among university students. American Journal of Orthopsychiatry, 77(4), 534-542.

Elliott, R., Sahakian, B. J., Herrod, J. J., Robbins, T. W., \& Paykel, E. S. (1997) Abnormal response to negative feedback in unipolar depression: Evidence for a diagnosis specific impairment. Journal of Neurology, Neurosurgery \& Psychiatry, 63(1), 74-82.

Eshel, N., \& Roiser, J. P. (2010). Reward and punishment processing in depression. Biological Psychiatry, 68(2), 118-124.

Estrada, M., Hernandez, P. R., \& Schultz, P. W. (2018). A longitudinal study of how quality mentorship and research experience integrate underrepresented minorities into STEM careers. CBE-Life Sciences Education, 17(1) $\operatorname{ar9}$.

Evans, T. M., Bira, L., Gastelum, J. B., Weiss, L. T., \& Vanderford, N. L. (2018) Evidence for a mental health crisis in graduate education. Nature Biotechnology, 36(3), 282.

Everson, H. T., Tobias, S., Hartman, H., \& Gourgey, A. (1993). Test anxiety and the curriculum: The subject matters. Anxiety, Stress, and Coping, 6(1) $1-8$

Flaherty, C. (2018). New study says graduate students' mental health is a "crisis." Retrieved November 29, 2019, from www.insidehighered.com/ news/2018/03/06/new-study-says-graduate-students-mental-health -crisis

Forsythe, A., \& Johnson, S. (2017). Thanks, but no-thanks for the feedback Assessment \& Evaluation in Higher Education, 42(6), 850-859.

Garlow, S. J., Rosenberg, J., Moore, J. D., Haas, A. P., Koestner, B., Hendin, H., \& Nemeroff, C. B. (2008). Depression, desperation, and suicidal ideation in college students: Results from the American Foundation for Suicide Prevention College Screening Project at Emory University. Depression and Anxiety, 25(6), 482-488.

Gelso, C. J., \& Lent, R. W. (2000). Scientific training and scholarly productivity: The person, the training environment, and their interaction. In Brown S. D., \& Lent, R. W. (Eds.), Handbook of counseling psychology (pp. 109139). Hoboken, NJ: John Wiley \& Sons Inc.

Gilbert, P., Baldwin, M. W., Irons, C., Baccus, J. R., \& Palmer, M. (2006) Self-criticism and self-warmth: An imagery study exploring their relation to depression. Journal of Cognitive Psychotherapy, 20(2), 183.

Gilbert, P., McEwan, K., Bellew, R., Mills, A., \& Gale, C. (2009). The dark side of competition: How competitive behaviour and striving to avoid inferiority are linked to depression, anxiety, stress and self-harm. Psychology and Psychotherapy: Theory, Research and Practice, 82(2), 123-136.

Gin, L. E., Rowland, A. A., Steinwand, B., Bruno, J., \& Corwin, L. A. (2018) Students who fail to achieve predefined research goals may still experience many positive outcomes as a result of CURE participation. CBELife Sciences Education, 17(4), ar57.

Glesne, C., \& Peshkin, A. (1992). Becoming qualitative researchers: An introduction. London, England, UK: Longman

Grav, S., Hellzèn, O., Romild, U., \& Stordal, E. (2012). Association between social support and depression in the general population: The HUNT 
study, a cross-sectional survey. Journal of Clinical Nursing, 21(1-2), 111 120.

Guest, G., Bunce, A., \& Johnson, L. (2006). How many interviews are enough? An experiment with data saturation and variability. Field Methods, 18(1), $59-82$.

Hancock, D. R. (2002). Influencing graduate students' classroom achievement, homework habits and motivation to learn with verbal praise. Educational Research, 44(1), 83-95.

Hannah, D. R., \& Lautsch, B. A. (2011). Counting in qualitative research: Why to conduct it, when to avoid it, and when to closet it. Journal of Management Inquiry, 20(1), 14-22.

Heatherton, T. F., \& Wyland, C. L. (2003). Assessing self-esteem. In Lopez, S. J., \& Snyder, C. R. (Eds.), Positive psychological assessment: A handbook of models and measures (pp. 219-233). Washington, DC: American Psychological Association. https://doi.org/10.1037/10612-014.

Henderlong, J., \& Lepper, M. R. (2002). The effects of praise on children's intrinsic motivation: A review and synthesis. Psychological Bulletin, 128(5), 774.

Henry, M. A., Shorter, S., Charkoudian, L., Heemstra, J. M., \& Corwin, L. A (2019). FAIL is not a four-letter word: A theoretical framework for exploring undergraduate students' approaches to academic challenge and responses to failure in STEM learning environments. CBE-Life Sciences Education, 18(1), ar11.

Hernandez, P. R., Woodcock, A., Estrada, M., \& Schultz, P. W. (2018). Undergraduate research experiences broaden diversity in the scientific workforce. BioScience, 68(3), 204-211.

Hish, A. J., Nagy, G. A., Fang, C. M., Kelley, L., Nicchitta, C. V., Dzirasa, K., \& Rosenthal, M. Z. (2019). Applying the stress process model to stress-burnout and stress-depression relationships in biomedical doctoral students: A cross-sectional pilot study. CBE-Life Sciences Education, 18(4), ar51.

Howell, E., \& McFeeters, J. (2008). Children's mental health care: Differences by race/ethnicity in urban/rural areas. Journal of Health Care for the Poor and Underserved, 19(1), 237-247.

Hysenbegasi, A., Hass, S. L., \& Rowland, C. R. (2005). The impact of depression on the academic productivity of university students. Journal of Mental Health Policy and Economics, 8(3), 145

Ibrahim, A. K., Kelly, S. J., Adams, C. E., \& Glazebrook, C. (2013). A systematic review of studies of depression prevalence in university students. Journal of Psychiatric Research, 47(3), 391-400.

Intemann, K. (2009). Why diversity matters: Understanding and applying the diversity component of the National Science Foundation's broader impacts criterion. Social Epistemology, 23(3-4), 249-266.

Ishiyama, J. (2002). Does early participation in undergraduate research benefit social science and humanities students? College Student Journal, 36(3), 381-387.

Jenkins, S. R., Belanger, A., Connally, M. L., Boals, A., \& Durón, K. M. (2013). First-generation undergraduate students' social support, depression, and life satisfaction. Journal of College Counseling, 16(2), 129-142.

Jobst, A., Sabass, L., Palagyi, A., Bauriedl-Schmidt, C., Mauer, M. C., Sarubin N., ... \& Zill, P. (2015). Effects of social exclusion on emotions and oxytocin and cortisol levels in patients with chronic depression. Journal of Psychiatric Research, 60, 170-177.

Jones, K. P., \& King, E. B. (2014). Managing concealable stigmas at work: A review and multilevel model. Journal of Management, 4O(5), 1466-1494.

Jones, M. T., Barlow, A. E., \& Villarejo, M. (2010). Importance of undergraduate research for minority persistence and achievement in biology. Journal of Higher Education, 81(1), 82-115.

Jones, N. P., Papadakis, A. A., Hogan, C. M., \& Strauman, T. J. (2009). Over and over again: Rumination, reflection, and promotion goal failure and their interactive effects on depressive symptoms. Behaviour Research and Therapy, 47(3), 254-259.

Judd, L. L., Paulus, M. J., Schettler, P. J., Akiskal, H. S., Endicott, J., Leon, A. C., ... \& Keller, M. B. (2000). Does incomplete recovery from first lifetime major depressive episode herald a chronic course of illness? American Journal of Psychiatry, 157(9), 1501-1504.

Kahn, J. H., \& Garrison, A. M. (2009). Emotional self-disclosure and emotional avoidance: Relations with symptoms of depression and anxiety. Journal of Counseling Psychology, 56(4), 573.
Kataoka, S. H., Zhang, L., \& Wells, K. B. (2002). Unmet need for mental health care among US children: Variation by ethnicity and insurance status. American Journal of Psychiatry, 159(9), 1548-1555.

Kreger, D. W. (1995). Self-esteem, stress, and depression among graduate students. Psychological Reports, 76(1), 345-346.

Krumpal, I. (2013). Determinants of social desirability bias in sensitive surveys: A literature review. Quality \& Quantity, 47(4), 2025-2047.

Landis, J. R., \& Koch, G. G. (1977). An application of hierarchical kappa-type statistics in the assessment of majority agreement among multiple observers. Biometrics, 33(2), 363-374.

Laursen, S., Hunter, A.-B., Seymour, E., Thiry, H., \& Melton, G. (2010). Undergraduate research in the sciences: Engaging students in real science. Hoboken, NJ: Wiley.

Limeri, L. B., Asif, M. Z., Bridges, B. H., Esparza, D., Tuma, T. T., Sanders, D., ... \& Maltese, A. V. (2019). "Where's my mentor?" Characterizing negative mentoring experiences in undergraduate life science research. CBE-Life Sciences Education, 18(4), ar61.

Link, B. G., \& Phelan, J. C. (2001). Conceptualizing stigma. Annual Review of Sociology, 27(1), 363-385.

Luyten, P., Sabbe, B., Blatt, S. J., Meganck, S., Jansen, B., De Grave, C., ... \& Corveleyn, J. (2007). Dependency and self-criticism: Relationship with major depressive disorder, severity of depression, and clinical presentation. Depression and Anxiety, 24(8), 586-596.

Mabrouk, P. A., \& Peters, K. (2000). Student perspectives on undergraduate research (UR) experiences in chemistry and biology. CUR Quarterly, 21(1), 25-33.

Maxwell, J. A. (2010). Using numbers in qualitative research. Qualitative Inquiry, 16(6), 475-482.

Mongrain, M., \& Blackburn, S. (2005). Cognitive vulnerability, lifetime risk, and the recurrence of major depression in graduate students. Cognitive Therapy and Research, 29(6), 747-768.

Nagy, G. A., Fang, C. M., Hish, A. J., Kelly, L., Nicchitta, C. V., Dzirasa, K., \& Rosenthal, M. Z. (2019). Burnout and mental health problems in biomedical doctoral students. CBE-Life Sciences Education, 18(2), ar27.

National Academies of Sciences, Engineering, and Medicine (NASEM). (2017) Undergraduate research experiences for STEM students: Successes, challenges, and opportunities. Washington, DC: National Academies Press. https://doi.org/10.17226/24622

NASEM. (2019). The science of effective mentorship in STEMM. Washington, DC: National Academies Press. Retrieved November 29, 2019, from www.nap.edu/download/25568

Osborne, J., \& Collins, S. (2001). Pupils' views of the role and value of the science curriculum: A focus-group study. International Journal of Science Education, 23(5), 441-467. https://doi.org/10.1080/09500690010006518

Porter, S. R., \& Whitcomb, M. E. (2005). Non-response in student surveys: The role of demographics, engagement and personality. Research in Higher Education, 46(2), 127-152.

President's Council of Advisors on Science and Technology. (2012). Engage to excel: Producing one million additional college graduates with degrees in science, Technology, Engineering, and mathematics. Washington, DC: U.S. Government Office of Science and Technology.

Prunuske, A. J., Wilson, J., Walls, M., \& Clarke, B. (2013). Experiences of mentors training underrepresented undergraduates in the research laboratory. CBE-Life Sciences Education, 12(3), 403-409.

Quinn, D. M., \& Earnshaw, V. A. (2011). Understanding concealable stigmatized identities: The role of identity in psychological, physical, and behavioral outcomes. Social Issues and Policy Review, 5(1), 160-190.

Rauckhorst, W. H., Czaja, J. A., \& Baxter Magolda, M. (2001). Measuring the impact of the undergraduate research experience on student intellectual development. Snowbird, UT: Project Kaleidoscope Summer Institute.

Saldaña, J. (2015). The coding manual for qualitative researchers. Thousand Oaks, CA: Sage.

Santiago, C. D., Kaltman, S., \& Miranda, J. (2013). Poverty and mental health: How do low-income adults and children fare in psychotherapy? Journal of Clinical Psychology, 69(2), 115-126.

Santini, Z. I., Koyanagi, A., Tyrovolas, S., Mason, C., \& Haro, J. M. (2015). The association between social relationships and depression: A systematic review. Journal of Affective Disorders, 175, 53-65. 
Schleider, J., \& Weisz, J. (2018). A single-session growth mindset intervention for adolescent anxiety and depression: 9-month outcomes of a randomized trial. Journal of Child Psychology and Psychiatry, 59(2), 160-170.

Seymour, E., \& Hewitt, N. M. (1997). Talking about leaving: Why undergraduates leave the sciences. Westview Press.

Seymour, E., \& Hunter, A.-B. (2019). Talking about leaving revisited. New York, NY: Springer.

Seymour, E., Hunter, A.-B., Laursen, S. L., \& DeAntoni, T. (2004). Establishing the benefits of research experiences for undergraduates in the sciences: First findings from a three-year study. Science Education, 88(4), 493-534.

Smith, D. T., Mouzon, D. M., \& Elliott, M. (2018). Reviewing the assumptions about men's mental health: An exploration of the gender binary. American Journal of Men's Health, 12(1), 78-89.

Sorkness, C. A., Pfund, C., Ofili, E. O., Okuyemi, K. S., Vishwanatha, J. K., Zavala, M. E., ... \& Deveci, A. (2017). A new approach to mentoring for research careers: The National Research Mentoring Network. BMC Proceedings, 11, 22

Sowislo, J. F., \& Orth, U. (2013). Does low self-esteem predict depression and anxiety? A meta-analysis of longitudinal studies. Psychological Bulletin, 139(1), 213.

Steger, M. F. (2013). Experiencing meaning in life: Optimal functioning at the nexus of well-being, psychopathology, and spirituality. In Wong, P. T. P. (Ed.), The human quest for meaning (pp. 211-230). England, UK: Routledge.

Strenta, A. C., Elliott, R., Adair, R., Matier, M., \& Scott, J. (1994). Choosing and leaving science in highly selective institutions. Research in Higher Education, 35(5), 513-547.
Text Depression Hotline. (2019). Crisis text line. Retrieved November 29, 2019, from www.crisistextline.org/depression

Thiry, H., \& Laursen, S. L. (2011). The role of student-advisor interactions in apprenticing undergraduate researchers into a scientific community of practice. Journal of Science Education and Technology, 20(6), 771-784.

Thompson, J. J., Conaway, E., \& Dolan, E. L. (2016). Undergraduate students' development of social, cultural, and human capital in a networked research experience. Cultural Studies of Science Education, 11(4), 959-990

Trenor, J. M., Miller, M. K., \& Gipson, K. G. (2011). Utilization of a think-aloud protocol to cognitively validate a survey instrument identifying social capital resources of engineering undergraduates. 118th American Society for Engineering Education Annual Conference and Exposition, Vancouver, BC, Canada.

Turner, R. J., \& Noh, S. (1988). Physical disability and depression: A longitudinal analysis. Journal of Health and Social Behavior, 29(1), 23-37.

Watson, D., \& Friend, R. (1969). Measurement of social-evaluative anxiety. Journal of Consulting and Clinical Psychology, 33(4), 448.

Weeks, J. W., Heimberg, R. G., Fresco, D. M., Hart, T. A., Turk, C. L., Schneier, F. R., \& Liebowitz, M. R. (2005). Empirical validation and psychometric evaluation of the Brief Fear of Negative Evaluation Scale in patients with social anxiety disorder. Psychological Assessment, 17(2), 179.

World Health Organization. (2018). Depression. Retrieved November 29, 2019, from www.who.int/news-room/fact-sheets/detail/depression

Wyatt, T., \& Oswalt, S. B. (2013). Comparing mental health issues among undergraduate and graduate students. American Journal of Health Education, 44(2), 96-107. 